\title{
Chapter 4 \\ Natural Flow Patterns and Structured People Dynamics: A Constructal View
}

\author{
A. Heitor Reis
}

\subsection{Introduction}

We show here that flow patterns similar to those that emerge in nature can also be observed in flows of people and commodities and can be understood in light of the same principle - the Constructal Law. River basins are examples of naturally organized flow architectures whose scaling properties have been noticed long ago. We show that these scaling laws can be anticipated based on constructal theory, which views the pathways by which drainage networks develop in a basin not as the result of chance but as flow architectures that originate naturally as the result of minimization of the overall resistance to flow. Next we show that the planetary circulations and the main global climate zones may also be anticipated based on the same principle. Finally, we speculate that the same principle governs "rivers of people," whose architecture develops in time to match the purpose of optimizing access within a territory.

\subsection{Patterns in Natural Flows: The River Basins Case}

Flow architectures are everywhere in nature, from the planetary circulation to the smallest scales. In the inanimate world, we can observe an array of motions that exhibit organized flow architectures: general atmospheric circulation, oceanic currents, eddies at the synoptic scale, river drainage basins, etc. In living structures, fluids circulate in special flow structures such as lungs, kidneys, arteries, and veins in animals and roots, stems, and leaves in plants.

Rivers are large-scale natural flows that play a major role in the shaping of the Earth's surface. River morphology exhibits similarities that are documented extensively in geophysics treatises. For example, Rodríguez-Iturbe and Rinaldo 1997) provided a broad list of allometric and scaling laws involving the geometric parameters of the river channels and of the river basins.

In living structures, heat and mass flow architectures develop with the purpose of dissipating minimum energy, thereby reducing the food or fuel requirement, and making all such systems more "fit" for survival Reis et al., 2004, 2006b). 
Fractal geometry has been used to describe river basin morphology (e.g., Cieplak et al, 1998; :Rodríguez-Iturbe and Rinaldo 1997). Fractals do not account for dynamics, hence are descriptive rather than predictive.

Different from the fractal description, constructal theory views the naturally occurring flow structures (their geometric form) as the end result of a process of area to point flow access maximization with the objective of providing minimal resistance to flow (see Bejan 2000; Bejan and Lorente 2004). The Constructal Law first put forward by Bejan in 1996 states that "for a finite-size system to persist in time (to live), it must evolve in such a way that it provides easier access to the imposed (global) currents that flow through it."

What is new with Constructal theory is that it unites geometry with dynamics in such a way that geometry is not assumed in advance but is the end result of a tendency in time. Constructal theory is predictive in the sense that it can anticipate the equilibrium flow architecture that develops under existing constraints. In contrast with fractal geometry, self-similarity need not be alleged previously, but appears as a result of the constructal optimization of river networks.

\subsubsection{Scaling Laws of River Basins}

River basins are examples of area-to-point flows. Water is collected from an area and conducted through a network of channels of increasing width up to the river mouth. River networks have long been recognized as being self-similar structures over a range of scales. In general, small streams are tributaries of the next bigger stream in such a way that flow architecture develops from the smallest scale to the largest scale, $\omega$ (Fig. 4.1).

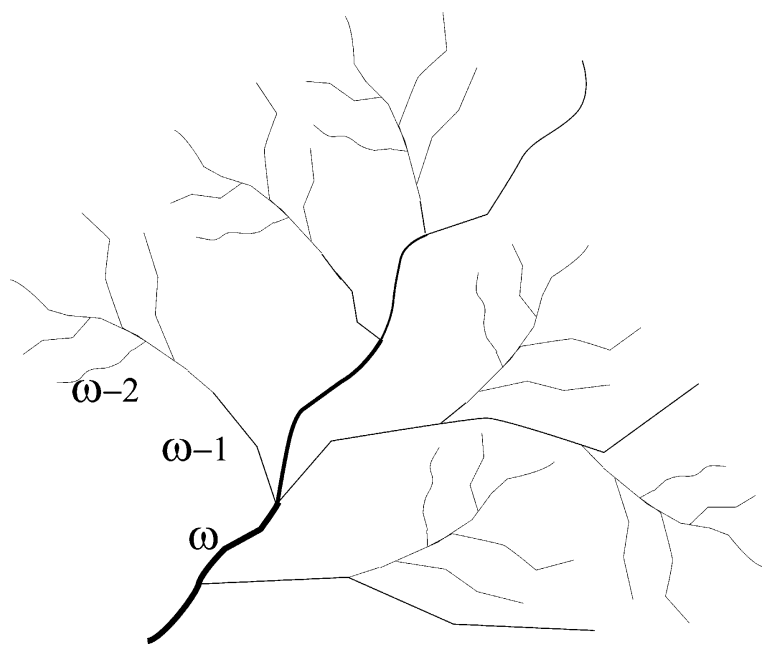

FIGURE 4.1. Hierarchical flow architecture in a river basin. Streams of order $\omega_{i-1}$ are tributaries of streams of order $\omega$ 
The scaling properties of river networks are summarized in well-known laws Beven, 1993). If $\mathrm{L}_{\mathrm{i}}$ denotes the average of the length of the streams of order $\mathrm{i}$, Horton's law of stream lengths states that the ratio

$$
\mathrm{L}_{\mathrm{i}} / \mathrm{L}_{\mathrm{i}-1}=\mathrm{R}_{\mathrm{L}}
$$

is a constant Horton 1932: see also Raft et al. 2003: Rodríguez-Iturbe and Rinaldo 1997). Here, the constant $\mathrm{R}_{\mathrm{L}}$ is Horton's ratio of channel lengths. On the other hand, if $\mathrm{N}_{\mathrm{i}}$ is the number of streams of order i, Horton's law of stream numbers asserts constancy of the ratio

$$
\mathrm{N}_{\mathrm{i}-1} / \mathrm{N}_{\mathrm{i}}=\mathrm{R}_{\mathrm{B}}
$$

where $R_{B}$ is Horton's bifurcation ratio. In river basins, $R_{L}$ ranges between 1.5 and 3.5 and is typically 2 , while $R_{B}$ ranges between 3 and 5 , typically 4 Rodríguez-Iturbe and Rinaldo, 1997).

The mainstream length $\mathrm{L}_{\omega}$ and the area $\mathrm{A}_{\omega}$ of a river basin with streams up to order $\omega$ are related through Hack's law Hack 1957: see also Rodríguez-Iturbe and Rinaldo 1997; Schuller et al.2001):

$$
\mathrm{L}_{\omega}=\alpha\left(\mathrm{A}_{\omega}\right)^{\beta}
$$

where $\alpha \sim 1.4$ and $\beta \sim 0.568$ are constants.

If we define a drainage density $\mathrm{D}_{\omega}=\mathrm{L}_{\mathrm{T}} / \mathrm{A}$ (where $\mathrm{L}_{\mathrm{T}}$ is the total length of streams of all orders and $\mathrm{A}$ the total drainage area) and a stream frequency $\mathrm{F}_{\mathrm{s}}=\mathrm{N}_{\mathrm{s}} / \mathrm{A}$ (where $\mathrm{N}_{\mathrm{s}}$ is the number of streams of all orders) then Melton's law Melton 1958; see also Raft et al, 2003; Rodríguez-Iturbe and Rinaldo 1997) indicates that the following relation holds:

$$
\mathrm{F}_{\mathrm{s}}=0.694\left(\mathrm{D}_{\omega}\right)^{2}
$$

Other scaling laws relating discharge rate with river width, depth, and slope may be found in the book by Rodríguez-Iturbe and Rinaldo 1997).

The scaling laws of geometric features of river basins have been predicted based on Constructal theory, which views the pathways by which drainage networks develop in a basin not as the result of chance but as flow architectures that originate naturally as the result of minimization of the overall resistance to flow Bejan 2006; Reis 2006a).

The ratios of constructal lengths of consecutive streams match Horton's law for the same ratio, while the same holds for the number of consecutive streams that match Horton's law of ratios of consecutive stream numbers.

Hack's law is also correctly anticipated by the constructal relations that provide Hack's exponent accurately.

Melton's law is anticipated approximately by the constructal relationships that indicate 2.45 instead of 2 for Melton's exponent. However, the difficulty to calculate correctly the drainage density and the stream frequency from field data indicates that some uncertainty must be assigned to Melton's exponent Reis 2006a). 


\subsection{Patterns of Global Circulations}

Here, constructal theory is extended to the problem of atmospheric and oceanic circulation driven by heating from the sun. Climate means the average thermohydrodynamic conditions that prevail over a significant period (generally 30 years) at a particular region of Earth's surface. Due to nonuniform heating, flows develop on the Earth's surface carrying heat from hot to cold regions. Atmospheric and oceanic circulations of a wide range of magnitudes participate in this transfer. Coupling between different scales of heat and mass flows is highly non-linear, thereby making prediction of the thermo-hydrodynamic state of the atmosphere a very hard task.

Thermodynamically, the Earth as a whole is a nonequilibrium closed systema flow system with heat input and heat rejection, and with internal flows. It is not an isolated thermodynamic system. Furthermore, the Earth's thermodynamic system is not in a steady state, as can be concluded from the observational evidence that temperature and pressure have temporal variations. However, if we consider local values averaged over a long period, temperature and pressure become time independent even if their spatial variation is preserved. This procedure implies loss of information of short-period phenomena, but it allows the construction of useful steady-state models of the whole system. These models capture the long-term performance of the Earth system and allow useful predictions about climate.

Atmospheric and oceanic circulations are the largest flow structures on Earth. Modeling of such flow structures relies on deterministic equations, e.g., conservation of mass, energy, angular momentum, and momentum, some of which are nonlinear and give rise to additional terms that result from the averaging procedure. The closure of such a system of equations is not easy and is achieved with the help of empirical information. In spite of the large number of parameters used, such models have shed light on global circulation and climate, and have served as reminders that theory is needed.

A different approach is made possible by constructal theory (see Bejan and Reis 2005; Reis and Bejan 2006). Although constructal theory also relies on mass and energy conservation, it derives the actual flow field (the flow architecture) from the maximization of the flow access performance of the whole system under the existing constraints. The nonuniform heating of the Earth's surface and atmosphere drives the Earth circulation. According to constructal theory, the purpose of the circulation (the objective of any flow with configuration) is to provide maximum access to the currents that flow, in this case to the transfer of heat from the equatorial zone to the polar caps. The zones and caps are organized in such a way that they perform this transport in the most efficient way, which is the one that maximizes the heat flow or, alternatively, by the flow structure that minimizes the resistance to the global heat flow. The theory showed that the poleward heat flow is maximized if the Earth's surface is partitioned into a heat source between $25^{\circ} 40^{\prime} \mathrm{N}$ and $25^{\circ} 40^{\prime} \mathrm{S}$, and two heat sinks located in the polar caps bounded by the latitudes $53^{\circ} 10^{\prime} \mathrm{N}$ and $\mathrm{S}$. Between the heat source 
and sinks, in each hemisphere, there is a third surface that participates in the heat transfer process and has an average temperature of $281.5 \mathrm{~K}$. These intermediate surfaces correspond to vertical circulating loops, as was seen when the average temperatures defining this partitioning of surfaces are included in the calculation of the flow variables of the model.

It is worth noting that the latitude $25^{\circ} 40^{\prime}$ corresponds very accurately to the boundary between the Hadley and Ferrel cells. Furthermore, the latitude $53^{\circ} 10^{\prime}$ is close to the latitude $60^{\circ}$, which is recognized as the boundary between the Ferrel and the polar cells that represent the mean meridional atmospheric circulation on Earth. In Fig. 4.2 we can observe the cells corresponding to the long-term latitudinal circulation: the Hadley cells, which start at the Equator and go close to $25^{\circ}$, the Polar cells that develop between each pole and latitude $60^{\circ}$, and the Ferrel cells located between the Hadley and the Polar cells. These cells are considered to drive the Ferrel cells, which develop between them.

It is a remarkable coincidence that the invocation of the Constructal Law predicts these latitudes as the optimal partitioning of the Earth's surface with respect to the heat flow along the meridian. The predicted average temperature of the Earth's surface, the convective conductance in the horizontal direction as well as other parameters defining the latitudinal circulation also match the observed values.

In a second part of the study Reis and Bejan 2006), the Constructal Law was invoked in the analysis of atmospheric circulation at the diurnal scale. Here the heat transport is optimized against the Ekman number. Even though this second optimization is based on very different variables than in the first part of the paper, it produces practically the same results for the Earth's surface temperature and the other variables. The Earth's average temperature difference between day and night was found to be approximately $7 \mathrm{~K}$, which matches the observed value. The accumulation of coincidences between theoretical predictions and natural facts adds weight to the claim that the Constructal Law is a law of nature Reis and Bejan 2006.

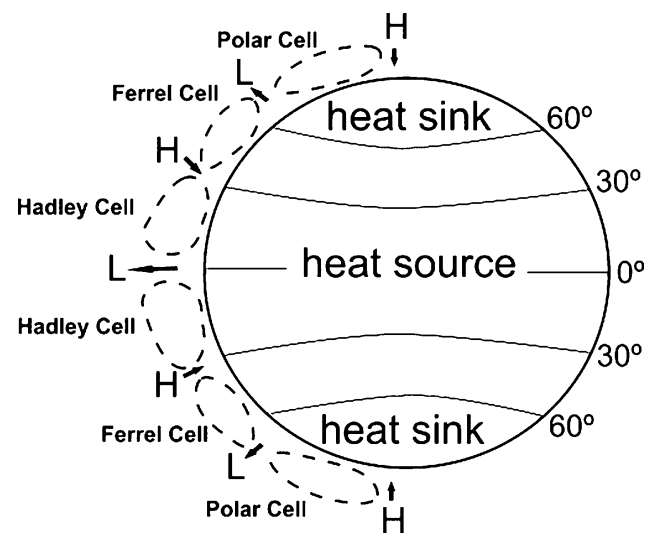

FIGURE 4.2. The main cells of global circulation that determine Earth's climate 


\subsection{Flows of People}

Individuals living in large cities usually have to travel long distances to carry out daily activities. Walking is the first mode of movement for people when they depart from home. Then they can use cars, buses, trains, or planes in the way to their destination. Each of these means of transportation uses a proper channel to move on. Public transportation exists because individuals agree in moving together in some direction. It is also a way of saving exergy, i.e., useful energy, and time. The movement of people is in the beginning disorganized (erratic, if we consider a group of individuals) showing the characteristics of diffusive flow, then becomes progressively organized (more and more people moving in the same way) as people move into larger streams. The speed of transportation also increases as individuals proceed from home to the larger avenues (Fig. 4.3). The global movement of people can be regarded as an area-to-point flow as people move from their homes to the largest way and then as a point-to-area flow as they disperse onto the area of destination. These patterns have been encountered before in many naturally organized flows (river basins, lungs, etc.) and occur in nature because they offer minimum global resistance to flow Bejan 2000.

Modeling flows of people may be carried out in a framework similar to flows of inanimate matter. In that case, we know the forces that drive the movement. Humans are not only subjected to external (physical) forces and constraints but are also subjected to "internal" driving forces. However, whatever the forces that drive individuals along a path i are (see Fig.4.3), they always result in internal energy dissipation (entropy generation) that can be represented by (see Reis 2006b):

$$
\dot{\mathrm{E}}_{\mathrm{i}}=\mathrm{R}_{\mathrm{i}} \mathrm{I}_{\mathrm{i}}^{2}
$$

where $\dot{\mathrm{E}}_{\mathrm{i}}$ means energy dissipation rate, $\mathrm{R}_{\mathrm{i}}$ is resistance to flow and $\mathrm{I}_{\mathrm{i}}=\Delta \mathrm{m}_{\mathrm{i}} / \Delta \mathrm{t}_{\mathrm{i}}$ is current, i.e., the ratio of mass $\Delta \mathrm{m}_{\mathrm{i}}$ (bodies, cars) that crosses the channel section to passage time $\Delta \mathrm{t}_{\mathrm{i}}$.

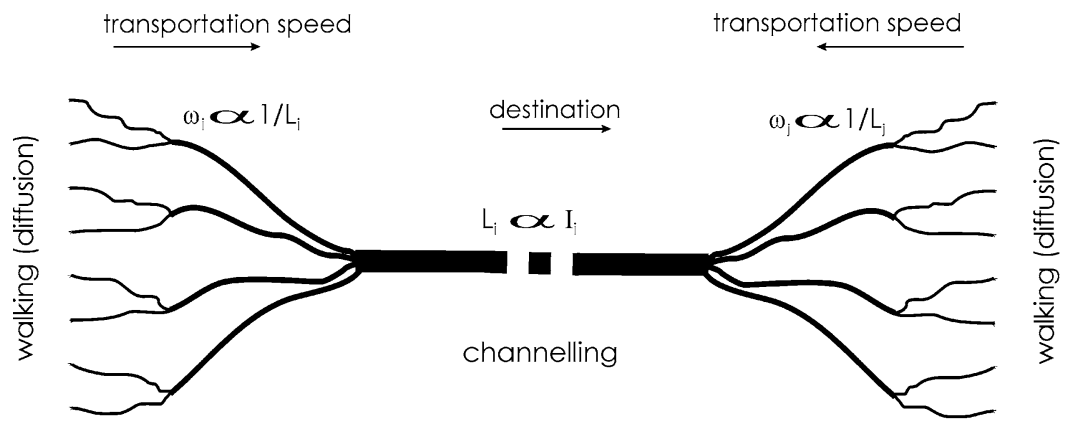

FIGURE 4.3. Area-to-point and point to area flows of people form a double tree. Constructal theory provides the optimal flow tree configuration 
The physical significance of resistance in flows of people can be inferred from Eq. 4.5) and corresponds to the energy that is destroyed by a current flowing at the rate of $1 \mathrm{~kg} / \mathrm{s}$. The resistance to flow depends on technological factors such as the efficiency and capacity of the available means of transportation as well as on the morphology of street and road networks and the topography of the territory.

The current I may vary during the day and usually matches permanent transportation needs corresponding to the existing economic and social activities of the communities. In this way, most of the times I must be considered as a constant while being also a constraint to the transportation system.

Finally, the energy is the physical prime-mover of the economic and social systems Reis 2006d. Everything that flows in these systems is driven by the available energies. Thus, energy is essential for keeping systems alive, and because it is scarce it must be used adequately. This is why a "living" system must optimize the use of energy in every particular activity or, what is the same, it must minimize the resistance to the respective internal flows [see Eq. (4.5)]. Therefore, flows of people are also a field of application of the Constructal Law.

Easier access means lesser global resistance to flow, i.e., better utilization of the available energy. In this way, "living" systems must develop internal flow structures that match this purpose. Modern societies have developed networks with the purpose of making the flows of people and goods easier and easier. People and goods flow through these networks in organized ways. These organized movements configure tree patterns as people move from home to destination (see Fig. 4.3). These tree architectures may be optimized under the Constructal Law. However, this does not mean that the existing flows of people and goods are optimized. From the point of view of the Constructal Law these are evolving flow structures that morph in time as a result of the struggle of the global system for better performance. What Constructal Theory provides is the optimum flow structure under the existing constraints and elects it as the equilibrium flow structure in the direction of which the actual configuration will move as the result from the struggle for better performance.

\subsubsection{Optimal Flow Tree}

As discussed before, individuals moving daily from one area to another follow paths in the transportation network that form flow trees. When starting from different points spread over an area people's movement (walking) is little organized, while converging to access points to the first means of transportation, which usually carry little numbers of people (cars, buses). As people move together, the resistance per unit length (resistivity) diminishes. The next step for diminishing flow resistance might be converging to railway stations in order to use trains that present lower flow resistivity and then, if it is the case, to accede airports to proceed by plane. The distribution of people over the destination area proceeds inversely, i.e., people do use means of successively higher resistivity while moving to their destinations. Each pattern of area-to-point and point-to-area flow shapes as a tree (Fig. 4.3). 
The form of the flow tree that offers the lowest resistance to flow of people under the existing constraints may be derived analytically as follows. Let $r_{i}, L_{i}$ and $\omega_{i}$ be the resistivity, the average distance traveled, and the number of pathways traveled by means of transportation of kind i, respectively. Then, the average resistance of each branch $i$ of the conceptual flow tree is given by

$$
\mathrm{R}_{\mathrm{i}}=\frac{\mathrm{r}_{\mathrm{i}} \mathrm{L}_{\mathrm{i}}}{\omega_{\mathrm{i}}}
$$

The total distance $\mathrm{L}$ to be traveled using $\mathrm{n}$ means of transportation-the branching level of the tree-is fixed,

$$
\sum_{\mathrm{i}=1}^{\mathrm{n}} \mathrm{L}_{\mathrm{i}}=\mathrm{L}
$$

as it is the total current I flowing in the tree

$$
\sum_{i=1}^{n} \omega_{i} I_{i}=n I
$$

where $I_{i}$ is people's current flowing in pathway i. Let $I_{i}=N_{i} / \Delta t_{i}$, where $N_{i}$ is the number of people transported at the average velocity $\mathrm{v}_{\mathrm{i}}$ through all the i pathways during the interval $\Delta \mathrm{t}_{\mathrm{i}}=\mathrm{L}_{\mathrm{i}} / \mathrm{v}_{\mathrm{i}}$. The energy dissipated in branch $\mathrm{i}$ per unit distance and per unit of current is $\dot{\mathrm{e}}_{\mathrm{i}}=\dot{\mathrm{E}}_{\mathrm{i}} / \mathrm{I}_{\mathrm{i}} \mathrm{L}_{\mathrm{i}}$, and is fixed because it depends on the performance of the means of transportation that move in that branch. Then by using Eqs. 4.5 and (4.6) we can write Eq. 4.8) as:

$$
\sum_{\mathrm{i}=1}^{\mathrm{n}} \omega_{\mathrm{i}}^{2} \frac{\dot{\mathrm{e}}_{\mathrm{i}}}{\mathrm{r}_{\mathrm{i}}}=\mathrm{nI}
$$

By minimizing the flow resistance (Eq. 4.6) under the existing constraints (Eqs. 4.7 and 4.9) we obtain

$$
\omega_{\mathrm{i}}=\lambda_{1} \mathrm{r}_{\mathrm{i}}
$$

and

$$
\mathrm{L}_{\mathrm{i}}=2 \lambda_{1}^{2} \lambda_{2} \mathrm{I}_{\mathrm{i}}
$$

where $\lambda_{1}$ and $\lambda_{2}$ are constants that may be calculated from Eqs. (4.7) and (4.8). The distances $\mathrm{L}_{\mathrm{i}}$ define the lengths of the branches of the tree shown in Fig. 4.3 Given that $\mathrm{I}_{\mathrm{i}}=\mathrm{I} / \omega_{\mathrm{i}}$, Eq. 4.11 may be rewritten as

$$
\mathrm{L}_{\mathrm{i}}=2 \lambda_{1}^{2} \lambda_{2} \frac{\mathrm{I}}{\omega_{\mathrm{i}}}
$$

or, in view of Eq. 4.10, as

$$
\mathrm{L}_{\mathrm{i}}=2 \lambda_{1} \lambda_{2} \frac{\mathrm{I}}{\mathrm{r}_{\mathrm{i}}}
$$


Equations 4.10 4.13 indicate that the best conceptual configuration-i.e., the best combination of all available pathways for area-to-point and point-to-area access-is a flow tree in which the number of pathways traveled by means of transportation of kind $i$ is proportional to the respective resistivity (see Eq.4.10), while the average length to be traveled varies inversely with resistivity (see Eq. 4.13). In this way, the "best flow tree" is composed of a large number of pathways of high resistivity and progressively smaller number of low-resistivity pathways. On the other hand, pathway length increases with decreasing resistivity. This means that the largest distances must be covered by low-resistivity means of transportation. Furthermore, as pathway length varies inversely with resistivity (Eq. 4.13), the largest current of people must flow along the longest pathway (Eq. 4.11).

Finally, Eq. 4.12 shows the geometric form of such a conceptual flow tree: the number of pathways must vary inversely with pathway length. A representation of such a tree is shown in Fig. 4.3

The double flow tree shown in Fig. 4.3 matches two constrains only, which are represented by Eqs. (4.7) and (4.8). However, real trees occur as the result of a much higher number of constraints, though their importance is of second order. The freedom to morph is limited by the existing street and road networks, terrain configuration, and other particularities that must also be considered as constraints. However being the result of millions of individual movements, flow patterns appear as a consequence of a collective perception that movement is easier when people move in some special pathways. This kind of "crowd intelligence" designs flow patterns in city and intercity networks of communication. Networks pre-exist to flow patterns but these define which parts of the existing networks must be used for easier flow access. Morphing of transportation networks in time occurs as a response to pressure of people in search for flow trees that allow best area-to-point and point-to-are flow access.

\subsubsection{Fossils of Flows of People}

The Constructal Law indicates that the pattern that develops in time is the one that provides maximum flow access (minimum resistance) under the existing constraints. This universal behavior (law) has been observed both in inanimate and animate systems (e.g. Bejan 2000, 2006; Reis, 2006a, b)

The first human communities that established in fixed places had to establish their own "farmland," i.e., the area that fed the community. Even in our time we can observe these "farmlands" that feed small rural communities, and the pathways that serve for transportation of goods and people (Fig. 4.4). Also in ancient times, movement of people between the settlements and the surrounding area designed flow pathways some of which can be seen still in the present time. They are fossils of ancient flows of people that remind us of how our ancestors solved area-to-point flow access problems.

In many of our cities that are of ancient origin, we can observe such fossil patterns which are reminiscent of ancient eras. Figure 4.5 represents an aerial 


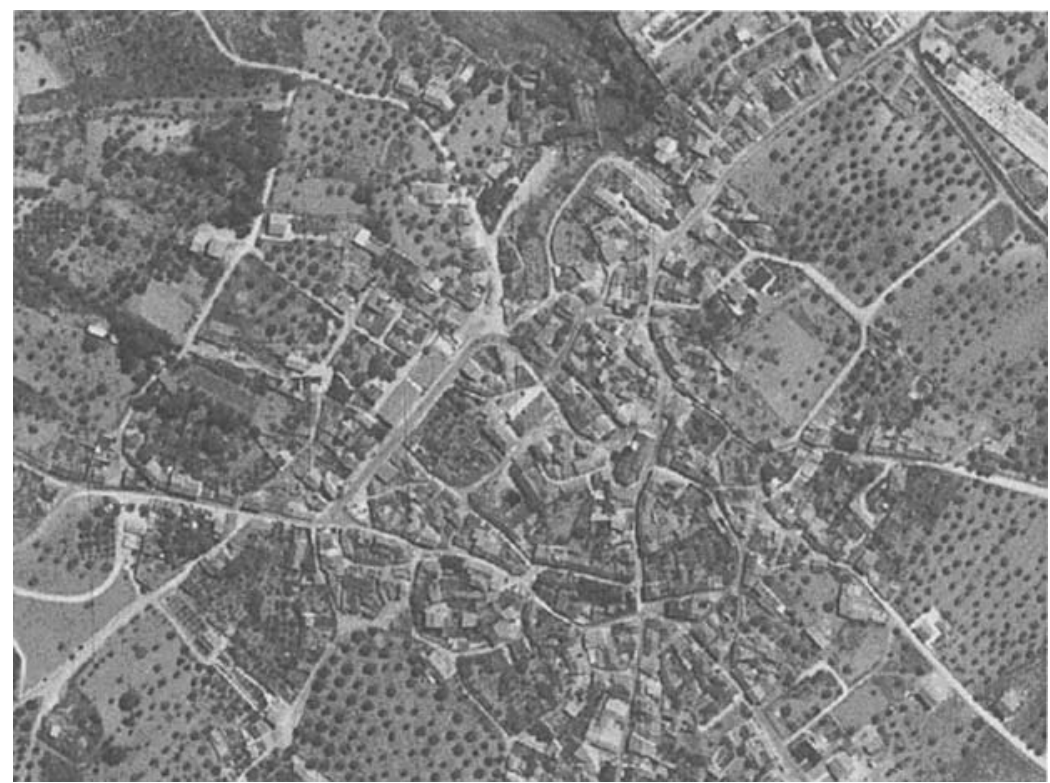

Figure 4.4. Rural community and the surrounding farmland. Pathway network serves the purpose of flow access of people and commodities (Courtesy of IGP, Portugal)

view of the city of Évora in the south of Portugal, which was named as world heritage by UNESCO. We can observe an inner nucleus that matches the ancient perimeter of the city under the Roman Empire, with a network of small streets which were suited for flows of people in those times. The street network reflects the randomness characteristic of walking, which was the main way of locomotion. The pattern reveals a great number of small streets with high resistivity to flow,

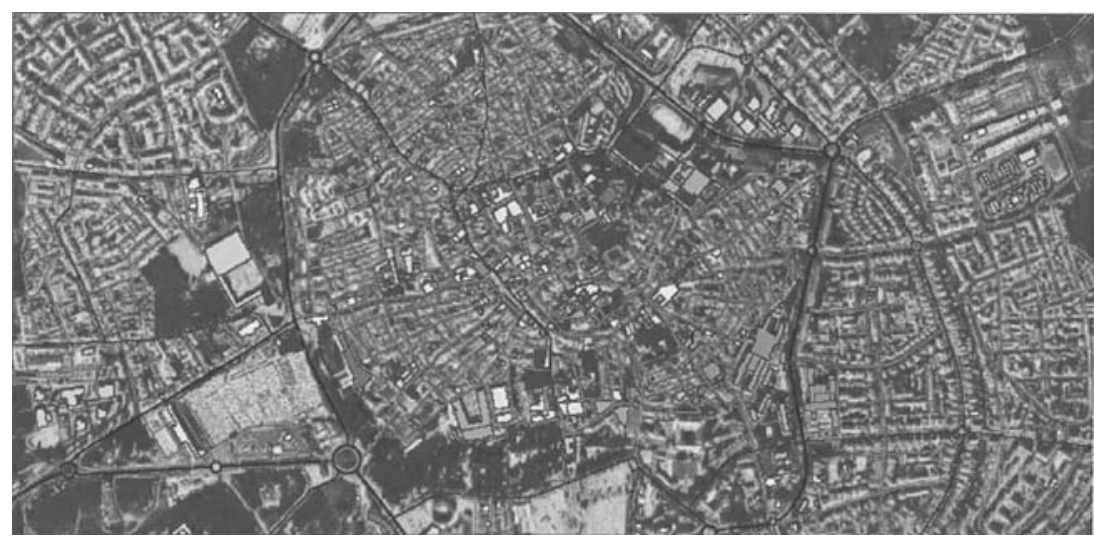

FIgURE 4.5. Historical center of Évora. Note that the gradient of people flow resistivity points to the city center, i.e., to the past (Courtesy of IGP, Portugal) 
in accordance with Eqs. (4.10) and 4.13). Next to the center a second pattern develops with broader and longer streets, which corresponds to the medieval part of the city, a time when horse and cart transportation were widespread. Note that reduction in flow resistivity entails increasing length of flow channels as stated by Eq. (4.13). Next we find the part of the city that corresponds to the times when automotive transportation (cars, buses, etc.) appeared. During the twentieth century the new streets became progressively wider and longer in response to increase in the automotive traffic.

In Fig. 4.6 we can also observe an aerial view of the downtown of Lisbon. The part to the right-hand side shows a circular street pattern developing around the medieval castle. Here we see again a great number of small streets corresponding to the high resistivity city network of the medieval era. In contrast with this part of the city, on the left-hand side we observe a very regular network of a smaller number of streets of lower resistivity. This part is from the middle of the eighteenth century after the big earthquake (1755), and was erected in order to match people flows of those times. In fact, during reconstruction, big ways were opened for people and goods transportation from the Lisbon harbor to the city center. Here we see again patterns that match Eqs. 4.10) and (4.13).

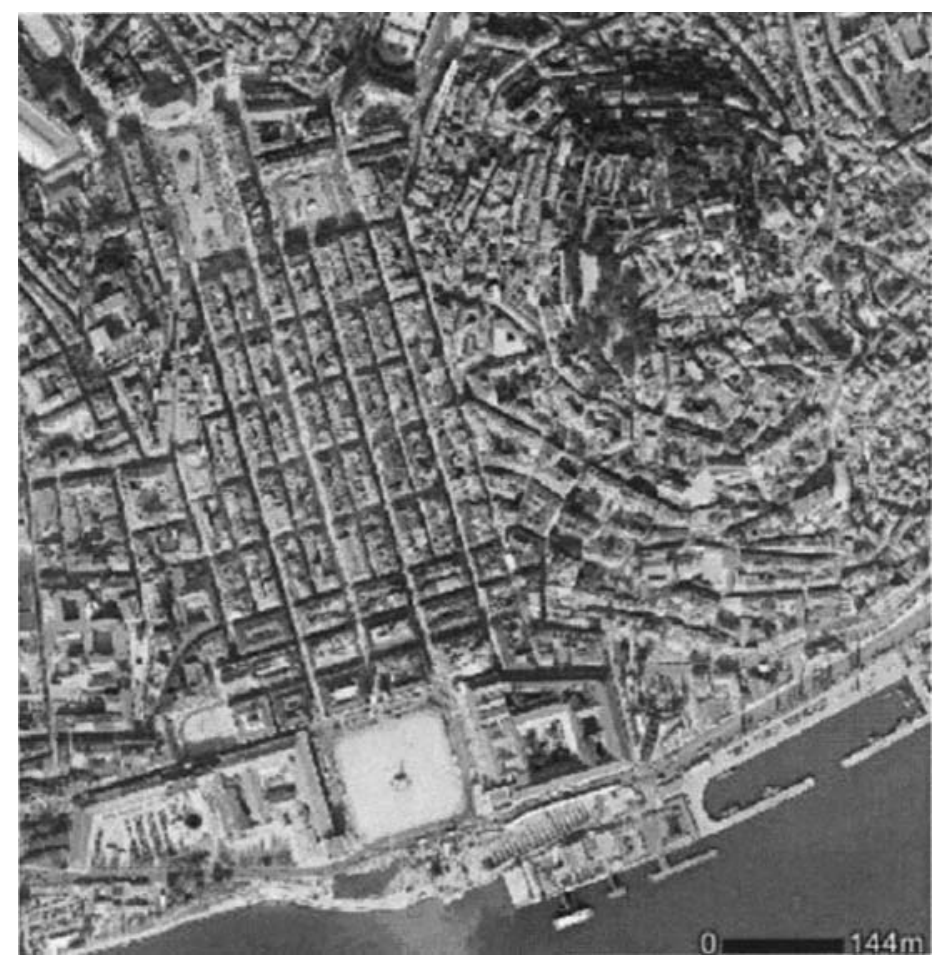

FIgURE 4.6. Downtown of Lisbon. Note the high resistivity area close to the medieval castle and the lower resistivity area of the eigtheenth century (Courtesy of IGP, Portugal) 
In this way, street networks tell us the story of development of people's flow patterns in history, which is also the story of the continuous search for easier flow access.

\subsection{Conclusions}

Constructal theory that has been successfully applied to planetary circulations and climate and to river basin morphology is shown to provide a useful framework for describing flows of people. We showed here, with simple examples, that intuitive rules of traffic organization can be anticipated based on principle, i.e., based on the Constructal Law. In addition, and similarly to the case of flows of inanimate matter, in the case of flows of people, flow patterns emerge as a necessary consequence of reduction of global flow resistances. These flow patterns point to decreasing resistivity to flows of people and commodities. Pathway length varies inversely with resistivity while pathway number increases with resistivity.

In summary, constructal theory provides a broad framework for the analysis of all types of flow including flows of people, which despite their complexity share common features with flows of inanimate matter.

\section{References}

Bejan, A. (2000) Shape and Structure, from Engineering to Nature, Cambridge University Press, Cambridge, UK.

Bejan, A. (2006) Advanced Engineering Thermodynamics, Chapter 13, 3rd Edn, Wiley, New York.

Bejan, A. and Lorente, S. (2004) The Constructal law and the thermodynamics of flow systems with configuration, Int. J. Heat Mass Transfer 47, 3203-3214.

Bejan, A. and Reis, A. H. (2005) Thermodynamic optimization of global circulation and climate, Int. J. Energy Res., 29(4), 303-316.

Bejan, A., Dincer, I., Lorente, S., Miguel, A. F. and Reis, A. H. (2004) Porous and Complex Flow Structures in Modern Technologies, Springer-Verlag, New York.

Beven K. (1993) Prophesy, reality and uncertainty in distributed hydrological modelling, Adv. Water Resources 16, 41-51.

Cieplak, M., Giacometti, A., Maritan, A., Rinaldo, A., Rodriguez-Iturbe, I. and Banavar, J. R. (1998) Models of Fractal River Basins, J. Stat. Phys. 91, 1-15.

Hack, J. T. (1957) Studies of longitudinal profiles in Virginia and Maryland. USGS Professional Papers 294-B, Washington DC, pp. 46-97.

Horton, R. E. (1932) Drainage basin characteristics, EOS Trans. AGU 13, 350-361.

Melton, M. A. (1958) Correlation structure of morphometric properties of drainage systems and their controlling agents, J. Geology 66, 35-56.

Raft, D. A., Smith, J. L. and Trlica, M. J. (2003) Statistical descriptions of channel networks and their shapes on non-vegetated hillslopes in Kemmerer, Wyoming, Hydrol. Processes 17, 1887-1897.

Reis, A. H. (2006a) Constructal view of scaling laws of river basins, Geomorphology $\mathbf{7 8}$, 201-206.

Reis, A. H. (2006b) Constructal theory: from engineering to Physics, and how flow systems develop shape and structure, Appl. Mech. Rev. 59, 269-282. 
Reis, A. H. (ed.) (2006c) Energy Based Analysis of Economic Sustainability, Perspectives in Econophysics, University of Évora, Portugal, pp. 147-159.

Reis, A. H. and Bejan, A. (2006) Constructal theory of global circulation and climate, Int. J. Heat Mass Transfer 49, 1857-1875.

Reis, A.H., Miguel, A.F. and Aydin, M. (2004) Constructal theory of flow architectures of the lungs, Med. Phys. 31(5), 1135-1140.

Reis, A. H., Miguel, A. F. and Bejan, A. (2006) Constructal particle agglomeration and design of air-cleaning devices, J. Phys. D: Appl. Phys. 39, 2311-2318.

Rodríguez-Iturbe, I. and Rinaldo A. (1997) Fractal River Basins, Cambridge University Press, New York.

Schuller, D. J., Rao, A. R. and Jeong, G. D. (2001) Fractal characteristics of dense stream networks, J. Hydrol. 243, 1-16. 